\title{
INFORMATION CULTURE AS A VALUABLE ELEMENT OF STRATEGIC INFORMATION MANAGEMENT
}

SUBMITTED: September 2020

REVISED: June 2021

PUBLISHED: October 2021

EDITOR: Robert Amor

DOI: $10.36680 / j . i t c o n .2021 .038$

\author{
Abiodun Akinyemi, Knowledge Transfer Associate, \\ School of Energy, Geoscience, Infrastructure and Society, Heriot-Watt University, Edinburgh, UK; \\ a.akinyemi@hw.ac.uk
}

Bilge Erdogan, Associate Professor, School of Energy, Geoscience, Infrastructure and Society, Heriot-Watt University, Edinburgh, UK;

b.erdogan@hw.ac.uk

Frédéric Bosché, Senior Lecturer in Infrastructure Programme Management, School of Engineering, Institute for Infrastructure and Environment, University of Edinburgh, Edinburgh, UK; f.bosche@ed.ac.uk

Derek O'Neil, Head of Planning, Careys Civil Engineering, Glasgow, UK;

Derek.ONeil@careysplc.co.uk

SUMMARY: This study proposes a strategy development framework for information management in a construction business. The framework covers the typical project lifecycle of a construction business which includes work winning and delivery. It incorporates a cultural analysis approach that covers the range of cultural manifestations expected in organisations. The approach also combines qualitative and quantitative research techniques. Application of the proposed framework for the development of information management strategy in a leading construction business showed that examining the information culture of the leadership and staff of the organisation is helpful in exposing the relevant informational issues. The case study also helped to validate that the proposed framework is a viable method for identifying and resolving informational issues inherent in construction organisations. Lastly, considering that the information management strategy developed in this study is for a typical construction business, other companies in the same domain will find the resource valuable.

KEYWORDS: information, culture, construction

REFERENCE: Abiodun Akinyemi, Bilge Erdogan, Frédéric Bosché, Derek O'Neil (2021). Information culture as a valuable element of strategic information management. Journal of Information Technology in Construction (ITcon), Vol. 26, pg. 700-719, DOI: 10.36680/j.itcon.2021.038

COPYRIGHT: (C) 2021 The author(s). This is an open access article distributed under the terms of the Creative Commons Attribution 4.0 International (https://creativecommons.org/licenses/by/4.0/), which permits unrestricted use, distribution, and reproduction in any medium, provided the original work is properly cited. 


\section{INTRODUCTION}

The delivery of the right information to the right people at the right time has significant implications for the success or failure of projects (Dzokoto, 2015). In construction operations, the complex relationships that exist between stakeholders inhibit effective identification of information requirements, which in turn hinders effective information creation, dissemination and use (Austin et al., 2002). Typical construction projects involve temporarily connected organisations working together. This unique cultural paradigm underpins some of the informational issues in the sector. It challenges the integration of knowledge within the construction process and can result in delays and disputes (Nasrun et al., 2014). Therefore, for the success of construction organisations and the projects they manage, it is critical to understand the culture surrounding the informational issues better. Previous Studies in this area have focused on developing analysis frameworks, presenting assessments, and describing case studies for understanding the impact of culture on information communication technologies for performance improvement in construction. However, none of these studies has proposed and validated a strategy development framework for information management that construction businesses can adopt. To bridge this gap, this study proposes a framework that helps to incorporate (i) the behaviour of information users, and (ii) the information management practices of a construction business in its development of an information strategy.

This paper is organised as follows. Section 2 describes the research method. Section 3 provides a review of literature on culture in general, information culture in the construction industry, and cultural analysis approaches applicable to this research. Section 4 details the conceptual framework of the proposed strategy development technique incorporating information culture. Section 5 describes a case study to demonstrate and validate the proposed strategy development framework, and Section 6 concludes this work.

\section{RESEARCH METHOD}

This research combines deductive and inductive approaches. The deductive element is focused on hypothesis development using literature review. The hypothesis generated is systematically tested to check if it holds in the context of this study. The inductive element involves carefully making observations and using the observations to create theories about a studied case. The case study data is collected through participant observation, interviews, record reviews, group discussions, questionnaire, and literature review.

Regarding participant observation, the first author worked in the studied organisation through the period of the study. This involved fitting in, gaining the trust of members of the organisation and, at the same time, remaining sufficiently detached to be able to carry out the observation.

The required interviews were carried out in person i.e., face-to-face where possible. Where the latter was not possible, video conferencing technologies - Skype (Microsoft, 2021a) and Microsoft Teams (Microsoft, 2021b) were used. The researcher conducted the interviews in an unstructured way, letting the interviewees speak freely about the relevant issues. About 100 unstructured interviews, targeted at the company leadership and key process owners, took place over a period of one year.

Regarding record reviews, the controlled documents supporting data management in the studied organisation were reviewed. In respect of group discussions, over 50 meetings involving process owners and information users took place to reconcile the differences in the information management views within the organisation. Lastly, a questionnaire survey was used for sampling the vast number of people interacting with the studied organisation's information.

\section{LITERATURE REVIEW}

\subsection{Strategic Information Management}

Strategic management in business seeks opportunities to add new resources, explore new territories, reduce cost or eliminate inefficiencies for competitive advantage or sustainment (IIBA, 2015). Examples of strategic management goals can be: the addition of new customers; improvements in quality, reliability, flexibility and decision making; or simply the struggle to survive. Strategic information management, by extension, examines the nexus between information systems and business strategy in achieving business objectives (Gajendran et al., 2012). It applies information systems and data to get meaningful information useful for better business performance. The benefit of strategic information management for businesses is usually in the form of savings in cost, time and effort related to decision making (Stewart, Mohamed and Daet, 2002). 


\subsection{Culture}

Culture is the characteristics of a group of people shaped by shared values, norms, practices, and artefacts (Gajendran et al., 2012). These shared manifestations of culture guide the way a group thinks, feels and acts regarding a subject. Cultural manifestations are important because they help in the perception of the culture of a group. The higher the level of cultural manifestation, the better the perception (Van Marrewijk, 2007). The cultural models by Hofstede (2001) and Rousseau (1990) identify key cultural manifestations. A review of those models shows that four important manifestations are core and essential in deciphering the culture of a group. These are described as follows:

- Values: these are deep manifestations of culture shaped by beliefs and underlying assumptions. Values inform the strategies applied in achieving the goals of an organisation. They may be difficult to detect or openly espoused. They are difficult to detect when they are unconsciously conceived or based on taken-for-granted perceptions or beliefs. They are openly espoused when they are reflected in the goals and strategies of an organisation (Gajendran et al., 2012).

- Norms: these are rules or socially accepted standards that define what is normal or to be expected in a group. Norms give people a way to gauge what is 'normal' in a specific context and at a specific time. Norms are derived from values but have a more direct influence on behaviour (Choo et al., 2006).

- Practices: these are patterns of behaviour, which are themselves repeated patterns of action, within a group. Practices within a group may exist in form of rituals (procedures) and celebrations (Schein, 2004).

- Artefacts: these are created to express information about culture. Examples of cultural artefacts include symbols e.g., colours, rituals e.g., greeting style, and heroes e.g., role models (Schein, 2004).

\subsection{Information culture in the construction industry}

Svärd (2014) posits that information culture is a set of human activities undertaken towards information. It relates to organisational values, norms and practices regarding the use, management, and control of information (Choo et al., 2006). Ginman (1993) found that a highly developed information culture is positively associated with good organisational practices and successful business performance; hence planning for information culture is mission critical. In construction, culture underpins the way actors interact with one another and behave with information (Dzokoto, 2015). Evaluation of literature on information culture in the construction industry reveals that researchers in the domain focused on developing frameworks, presenting assessments, and describing case studies for empirical understandings of the impact of culture on information communication technologies (ICTs) to assist with performance improvement.

Table 1 summarises evaluated literature and their contributions. Gajendran and Brewer $(2007,2012)$ and Dzokoto (2015) developed frameworks for assessment of information culture. Adriaanse and Voordijk (2005) and Issa and Haddad (2008) contributed research on the challenges culture brings to the application ICTs in construction. Anumba et al. (2006) and Gajendran and Brewer (2010, 2012) contributed case studies on the subject. None of these studies proposed a strategy development framework that can help construction businesses incorporate information culture in their information management strategies.

Table 1: Academic literature on information culture in the construction industry

\begin{tabular}{|c|c|c|c|c|c|}
\hline \multirow[b]{2}{*}{$\mathrm{S} / \mathbf{N}$} & \multirow[b]{2}{*}{ Source } & \multirow[b]{2}{*}{ Summary } & \multicolumn{3}{|c|}{ Contribution } \\
\hline & & & Framework & Review & Case Study \\
\hline 1 & Adriaanse \& Voordijk, 2005 & $\begin{array}{l}\text { This research analysed culture as an obstacle to the } \\
\text { effective use of ICT systems in construction projects }\end{array}$ & & $\sqrt{ }$ & \\
\hline 2 & Anumba et al., 2006 & $\begin{array}{l}\text { This research studied the impact of culture on the } \\
\text { integration of new ICT (GIS) in the construction } \\
\text { industry }\end{array}$ & & & $\sqrt{ }$ \\
\hline 3 & Gajendran \& Brewer, 2007 & $\begin{array}{l}\text { This research developed a cultural analysis framework } \\
\text { for the integration of information technology in } \\
\text { construction industry }\end{array}$ & $\sqrt{ }$ & & \\
\hline
\end{tabular}




\begin{tabular}{|c|c|c|c|c|c|}
\hline \multirow[b]{2}{*}{$\mathbf{S} / \mathbf{N}$} & \multirow[b]{2}{*}{ Source } & \multirow[b]{2}{*}{ Summary } & \multicolumn{3}{|c|}{ Contribution } \\
\hline & & & Framework & Review & Case Study \\
\hline 4 & Issa \& Haddad, 2008 & $\begin{array}{l}\text { This study assessed the impact of organisational } \\
\text { culture and information technology on knowledge } \\
\text { sharing in the construction industry }\end{array}$ & & $\sqrt{ }$ & \\
\hline 5 & Gajendran \& Brewer, 2010 & $\begin{array}{l}\text { This study discussed the impact of culture on the extent } \\
\text { of ICT integration within the context of a construction } \\
\text { project }\end{array}$ & & & $\sqrt{ }$ \\
\hline 6 & Brewer \& Gajendran, 2012 & $\begin{array}{l}\text { This study described the development of a process for } \\
\text { understanding the link between culture and the use of } \\
\text { ICT in temporary project organisations }\end{array}$ & $\sqrt{ }$ & & $\sqrt{ }$ \\
\hline 7 & Gajendran \& Brewer, 2012 & $\begin{array}{l}\text { This study discussed the impact of cultural } \\
\text { environment on the adoption of ICT in construction } \\
\text { project organisations }\end{array}$ & & & $\sqrt{ }$ \\
\hline 8 & Dzokoto, 2015 & $\begin{array}{l}\text { This research investigated actors in construction } \\
\text { organisations to test the similarity of their information } \\
\text { seeking behaviour }\end{array}$ & $\sqrt{ }$ & $\sqrt{ }$ & \\
\hline
\end{tabular}

\subsection{Culture assessment}

The level of harmony or ambiguity of cultural manifestations defines the different cultural paradigms that exist (Gajendran et al., 2012). One school of thought sees culture either as a variable or a root metaphor (Smircich, 1983). Culture as a variable provides a simplified and functional approach to understanding culture. From this perspective, culture has a causal relationship to organisational performance - implying that modification of the behaviour of members results in changes in organisational outcomes. Culture as a root metaphor opposes the view that organisational effectiveness can be attained through direct cultural manipulation as this fails to address the negative features of people's behaviour, such as resistance to change. Rather, it promotes expressiveness, ideation and symbolism.

Another school of thought sees culture from three perspectives: integration, differentiation and fragmentation (Martin, 2002). From the perspective of integration, culture is shared across the various levels of an organisation. For differentiation, unique cultures exist at group and individual levels, and shared culture does not exist across the organisation. From the perspective of fragmentation, there is lack of clarity in cultural manifestations and culture is unshared in the organisation.

Another school of thought examines culture from multiple orientations: technical, practical and emancipatory (Alvesson, 2002). The technical orientation focuses on identifying and manipulating cultural variables to achieve the intended culture outcomes. The practical orientation focuses on the removal of communication misunderstandings within organisational groups to foster cultural understanding. The emancipatory orientation focuses on shedding light on aspects of culture that are exploitative in order eliminate the challenges associated with them.

Gajendran et al. (2012) identified the alignment of the latter two schools of thought; combined them as integrationtechnical, differentiation-practical, and fragmentation-emancipation positions; and proposed the combinations for cultural analysis in project organisations.

- Cultural analysis with the integration-technical approach seeks to develop and extend shared cultures that are positive by focusing on ways to integrate them within organisations. This type of analysis generally focuses on coordination and monitoring of the diverse groups of participants, proposing systems to monitor the progress made towards the achievement of the stakeholders' goals. This approach is useful for studies that focus on fragmentation within groups in order to promote aligned and improved project outcomes (Baiden, Price and Dainty, 2006).

- The differentiation-practical approach seeks to understand communications between different subcultures (Ankrah and Langford, 2005). This type of cultural analysis assists in improving understanding between sub-cultures and can lead to conflict mitigation and enhanced project collaboration. It does 
not take an optimistic view of culture as in the technical-integration approach, rather it involves observing and interpreting organisations through appreciation (Wilimoft, 1997). Also, it does not advocate that managers control the values of their subordinates to achieve effective behaviours (Alvesson, 2002). By acknowledging misunderstanding, this approach accepts ambiguity and tries to remove it through symbolic communication.

- The fragmentation-emancipation approach seeks to understand the subjective informal aspects of project organisations in developing a better understanding of culture. This approach has ambiguity as a permanent state with different interpretations, paradoxes and multiple value systems being welcome. Understanding the ambiguities is the objective of cultural analysis using this method (Chan and Raisanen, 2009).

Gajendran et al. (2012) argue that a pragmatic way to analyse culture in organisations is to have the hybrid of the latter research methods. The integration-technical approach is of a functional paradigm because it involves manipulating variables. This can be achieved by quantitative analysis. The differentiation-practical and fragmentation-emancipation approaches can be categorised as non-functional because they do not involve quantitative data. They involve qualitative data obtained by observations and communication with the individuals in the studied group.

\section{PROPOSED STRATEGY DEVELOPMENT FRAMEWORK}

The proposed framework in this research is based on inductive reasoning (Bryman and Bell, 2015), as theories are to be generated from the data collected using interpretivism (Saunders, Lewis and Thornhill, 2009), philosophical stance which emphasises the meaningful nature of people's participation in cultural life. The aim of data collection is to capture quality evidence that will enable an analysis that will support the development of the right strategy for the studied business. The strategy analysis technique developed by IIBA (2015) is adopted for the proposed framework. The framework includes steps that must be undertaken in order to establish needs of critical importance and identify the right solution plans to address them. The framework also follows the recommendation of Gajendran et al. (2012) which argues that a pragmatic way to analyse culture in organisations is to combine the various cultural analysis approaches. In this case, a survey is used to capture data for quantitative analysis. Interviews, observations and a workshop are used to capture data for qualitative analysis.

Figure 1 shows the essential steps of the strategy development framework proposed in this research. The first step focuses on analysing the current state in order to understand the business need. The second step involves clarifying the vision and strategy of the organisation on information management. The outputs from these steps are then analysed in the third step, taking into consideration the limiting and promoting factors, in devising the appropriate change strategy for the organisation. Details of each step are discussed in subsections 4.1 -4.5.

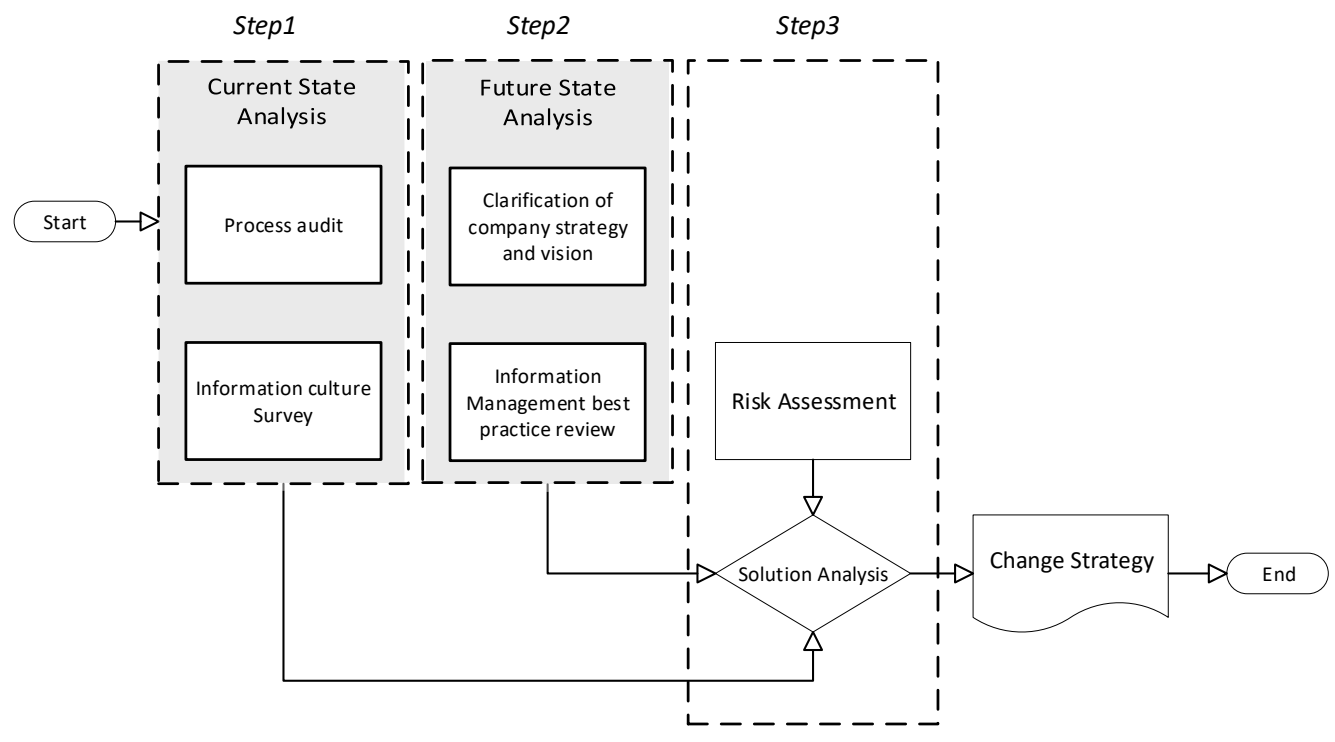

Figure 1: Strategy development framework 


\subsection{Process audit}

This activity involves audit of the existing information culture in an organisation by studying the current information processes and understanding the information management style in the organisation. This can be achieved through a number of meetings, interviews and focus group sessions with key individuals working in the company's operation. Also, applicable company documents (old surveys, procedures, guidance, document templates and forms) can be studied and an examination of the deployed information technology resources carried out.

\subsection{Information culture survey}

This activity involves a questionnaire to elicit qualitative and quantitative data on information culture from the various groups of people (professionals, support staff and company executives) who interact with project and company data through an organisation's information systems. The questionnaire (Akinyemi, 2021) should contain, as a minimum, questions on the following themes: user behaviour, management practices and demography. The user behaviour theme should include questions on values, norms and practices associated with information use in an organisation. The management practices theme should include questions on information technology (IT) support practices and data governance. The third theme, demography, should ask questions of the respondents regarding their roles, length of service, location, and business area, amongst others. The survey can also include open-ended qualitative questions for more detailed commentary. Figure 2 summarises the questions in the Akinyemi (2021) example. A majority of the survey sections contain questions with answers scaled to a Likert scale of 1 (strongly disagree) to 5 (strongly agree). 


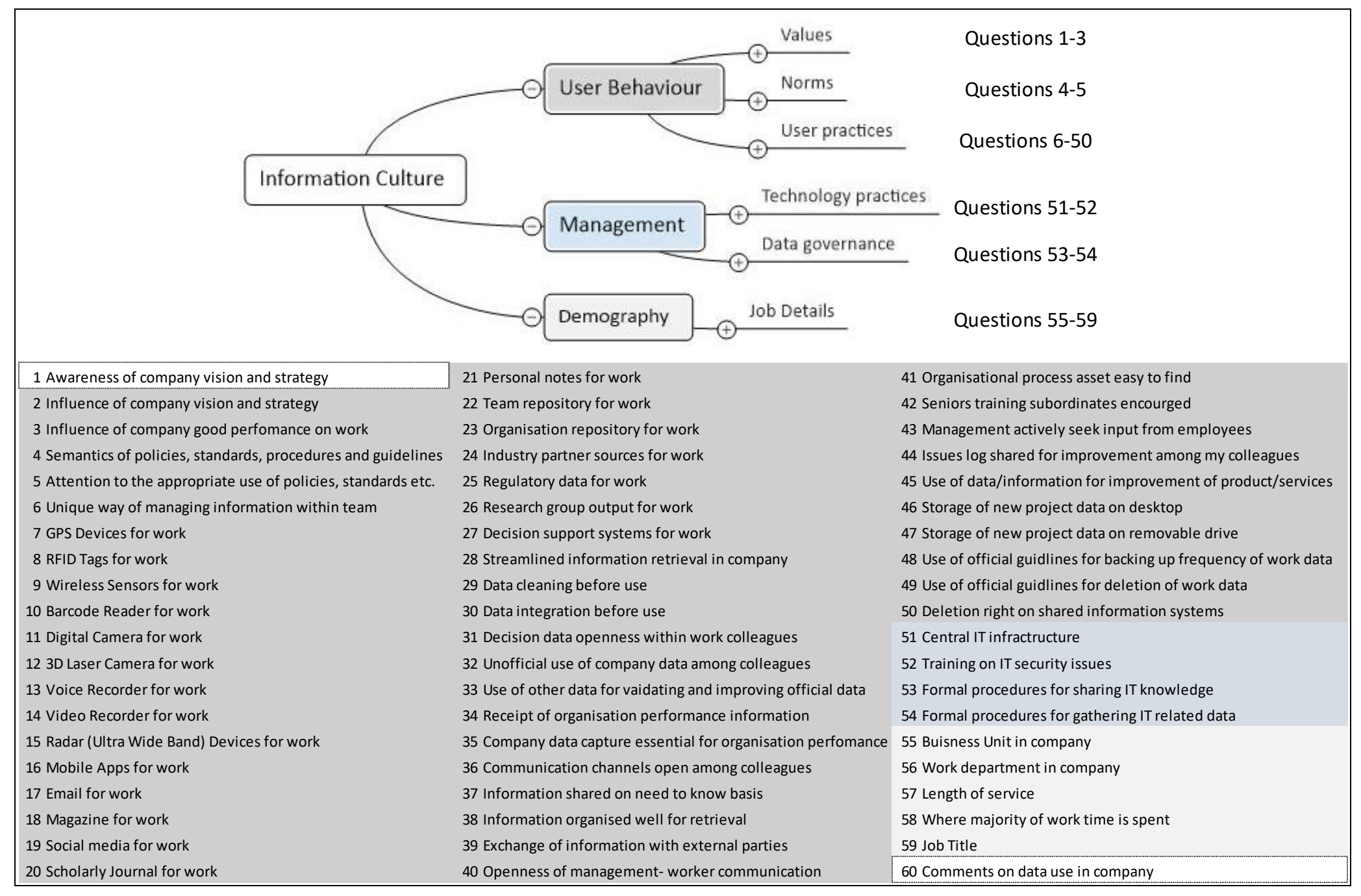

Figure 2: Questionnaire conceptual framework 


\subsection{Company vision and strategy}

This activity involves understanding the overall vision and strategy of a company by studying any documentation containing such information. It also involves conferring with the leadership of the organisation through formal meetings and informal discussions. In addition, any leadership presentation sessions must be monitored for any changes in the leadership's thinking. Lastly, a workshop session involving IT and core operations stakeholders should be used to clarify the scope of the change required and identify necessary actions to be taken.

\subsection{Information Management best practice review}

This activity involves investigation into what other organisations are doing that works very well. Also, practices that work very well in the different areas within the studied organisation should be investigated. Lastly, research into reported case studies in technical reports, published books and academic journals should be conducted. The best practice examples obtained from this exercise shall inform the change strategy.

\subsection{Risk assessment}

Using the results of the first two steps, Current State Analysis and Future State Analysis, a SWOT (Strengths, Weaknesses, Opportunities, and Threats) analysis (Gürel and Tat, 2017) is carried out to identify the internal and external factors that are helpful and detrimental to achieving the organisation's objectives. To define the strategy for the business, the result of the SWOT analysis should be presented to the company representative for validation. The company representative could then liaise with the operations board of the company and the technical experts supporting the effort in developing the change strategy to address the information management issues in the organisation. This should be done considering the recommendations from the SWOT analysis. The actions decided on should be ordered based on priority to form an implementation plan. A good ordering will ensure an incremental change that is beneficial to the organisation.

\section{CASE STUDY}

Presented in this study is the case of a leading construction business with the desire to radically turn around its information exchange performance and the overall productivity in its operations. The study domain for this case study includes the offices and construction project sites of the organisation which are spread across the UK. Our proposed strategy development framework is applied to develop an information management change strategy for the organisation. The detail is as follows.

\subsection{Current state analysis}

\subsubsection{Process audit}

The business is part of a group, so its chief officers report to the group board. The operation of the business is divided into two regions, North and South, headed by chief operating officers. Each region has multiple delivery heads responsible for the divisions within the region. Each region has multiple projects ongoing. These projects are headed by project managers supported by functional personnel including surveyors, planners and engineers. Depending on the scope of the project, the organisation can be the main contractor or a subcontractor. The organisation's activities on construction sites are supported by the site administrators who help to coordinate the activities of other functional groups - except for planning, Health Safety Environment and Quality (HSEQ), engineering and quantity surveying that directly deal with the project managers. Also on the sites are document controllers who manage the transmittal of all data and documents, and commercial administrators who report to the surveyors on projects. In order to manage the knowledge of a diverse and geographically dispersed group of professionals, the company has an intranet portal specifically designed for simplified access to shared data and information. The described structure is the basis for reporting, and it goes from lower-level staff to top-level managers. Its main challenge is the availability of accurate, up-to-date data for timely compliance checking and decision making.

A review of the result of the company's 2018 survey on its commercial activities reporting showed that surveyors in the organisation spend approximately $70 \%$ of their time compiling reports. This is estimated to cost an excess of about $£ 50,000 /$ month ( $£ 600,000 /$ annum). Also, $60 \%$ of the 885 survey respondents said they are required to enter the same data in more than one place either "a great deal" or "a lot of the times". This research's investigation of the site operations of the studied organisation confirms the latter as it revealed extensive use of paper-based 
forms, requiring manual completion and additional processing to get data to electronic format. For example, the quality department of the business has 195 standard forms with 3028 fields to be completed for a one-time completion of all the forms. Some of the forms contain similar fields, meaning the same information is captured repeatedly, which is unnecessary. The process is also error prone and time consuming.

Review of controlled documents on the company's intranet revealed that the existing departmental processes are siloed with each department creating procedures and policies that are not properly coordinated with other departments. Interviews and focus group sessions with the process owners revealed that there are several processes without procedures; there are procedures that don't reflect what really happens on sites; and there are work steps hidden from the view of people required for their performance. In addition, different meanings exist for some terms used in the organisation e.g., procedure and guidelines. Furthermore, roles with similar responsibilities but different designations exist, generating some confusion in the organisation. Attempts by stakeholders within the studied business to design work processes or information management strategies result in conflicts because of differing viewpoints. This allows 'feeder' cultures (Martin, 2002), in this case software vendors, to fade in and out of attention.

Regarding information systems, the IT department of the studied organisation has ongoing efforts to pull site data from different applications used in the business into a data warehouse. This is for the purpose of surfacing project data on live dashboards to aid decision support. This effort has yielded good result for the project planning team while other functional teams struggle to decide what data they would like to see surfaced. The reason for the struggle is because proper requirements gathering and analysis is missing from the effort. Observation of current data management in the organisation revealed that different tools - IT systems and document templates - are used for similar activities across project sites. In some cases, staff members are creating their own document templates for data capture without any coordination with relevant stakeholders around the solutions being applied. The implication of this is that there could be data integration issues when the different data sets are to be combined. Another problem with site data management is that people who should not have write access to some repositories do have them. Edits by such unauthorised persons can lead to data quality issues. However, because there seems to be no real consequences for such action, people tend to continue with the same substandard data practices.

\subsubsection{Information culture survey}

The survey questionnaire (Akinyemi, 2021) was implemented online using SurveyMonkey (SurveyMonkey Inc., 2019), and participants accessed the survey remotely via a web page link sent to their official email addresses. The chief executive of the company helped to raise awareness about the importance of the survey by sending out a post through the social networking platform on the company's intranet. The communications team of the company also sent out a message about the survey to the targeted groups within the company. The message contained financial incentive - in the form of prize draw - for completing the survey in order to ensure a good response rate. Each completed questionnaire formed a record in the exported data from the survey website. The database was subsequently cleaned and imported into SPSS (IBM Corporation, 2017) for statistical analysis, and NVivo (QSR International Pty Ltd, 2017) for text analysis on the qualitative responses.

In order to generalise the analysis result of the questionnaire survey on this research, the sample used must be representative of the population. According to Bryman (2012) the sample must be large enough to provide the necessary confidence in the result. The sampling technique explained in Taherdoost (2017) was applied. For this research, the population size - representing the people who interact with project and company data through the organisation's information systems - is 1,192, confidence interval of $95 \%$ is selected in line with management research, and 50\% selected for the percentage of population having a characteristic to maximise the variance and generate the maximum sample size as recommended by Bartlett et al. (2001). Given that the typical margin of error used in construction research is 10\% (Dzokoto, 2015), the required sample size for the case study is 89 . The questionnaire survey had 242 responses of which 171 of them were properly completed. Using the 171 responses as the sample surpasses the minimum requirement. In fact, it represents a margin of error of $6.95 \%$.

Based on the demographic data, $60 \%$ of the respondents work on project sites, while the remaining $40 \%$ work in client and company offices. These represent $11.8 \%$ and $20.7 \%$, respectively, of actual similar company staff as shown in Figure 3. $82 \%$ of the respondents work in technical roles e.g., engineering and design, while the remaining $20 \%$ work in support roles e.g., office management and human resources. These represent $14.1 \%$ and $13.3 \%$, respectively, of actual similar company staff as shown in Figure 3. The sizes of samples for site and 
technical staff relative to equivalent staff population fall within the $10 \%$ margin of error typical for construction research. Lastly, survey data shows that $38.5 \%$ of respondents have worked in the organisation for less than 3 years, $47 \%$ for $3-10$ years, and $14.3 \%$ for over 10 years.

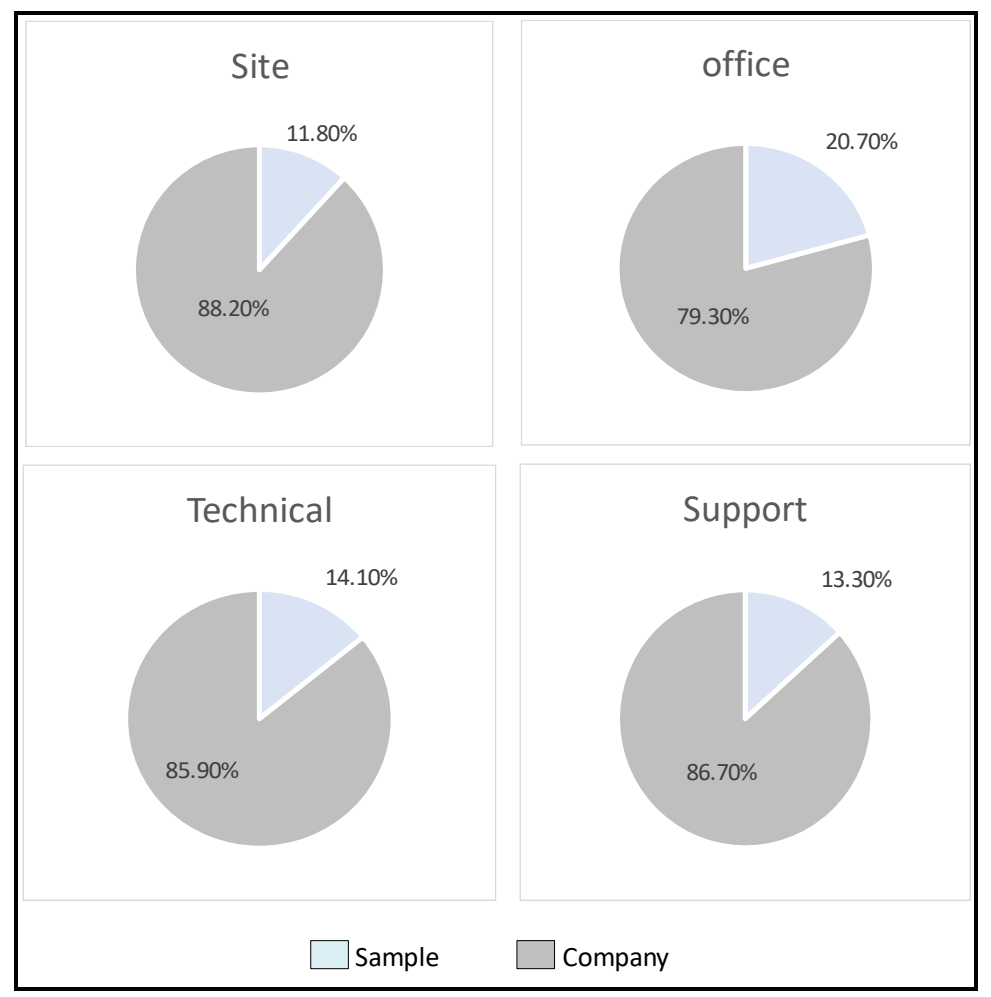

Figure 3: Survey sample versus actual company staff distribution

An exploratory factor analysis method - principal components analysis (PCA) (Jolliffe, 2011) - is used to reduce the number of variables collected from the survey. This technique is good for a large number of variables, as in this case, where we have 59 questions based on the framework in Figure 2. To select a subset of the larger set of variables, the highest correlations with the principal components are considered. Figure 4 shows the PCA results for the user behaviour theme of the information culture survey. To check that the data is suitable for factor analysis, Kaiser-Meyer-Olkin measure of sampling adequacy needs to be $\geq 0.6$ and the Bartlett's test of sphericity needs to be significant with a value $<0.5$. These tests were passed and a component loading value of 0.5 is selected as a threshold for including variables. The result shown in Figure 4(a) indicates the six components with eigenvalues greater than 1.0 - a requirement for component selection. These six components account for the majority of variance in the data set with a cumulative value of about $43.8 \%$. The mean score of each variable (as per responses to a given statement in the survey and shown in Figure 4(b)) indicates the degree of agreement of respondents to the statement on the 1-5 Likert scale. Mean values below 2.5 indicate disagreement with a statement, and values above 2.5 indicate agreement. 


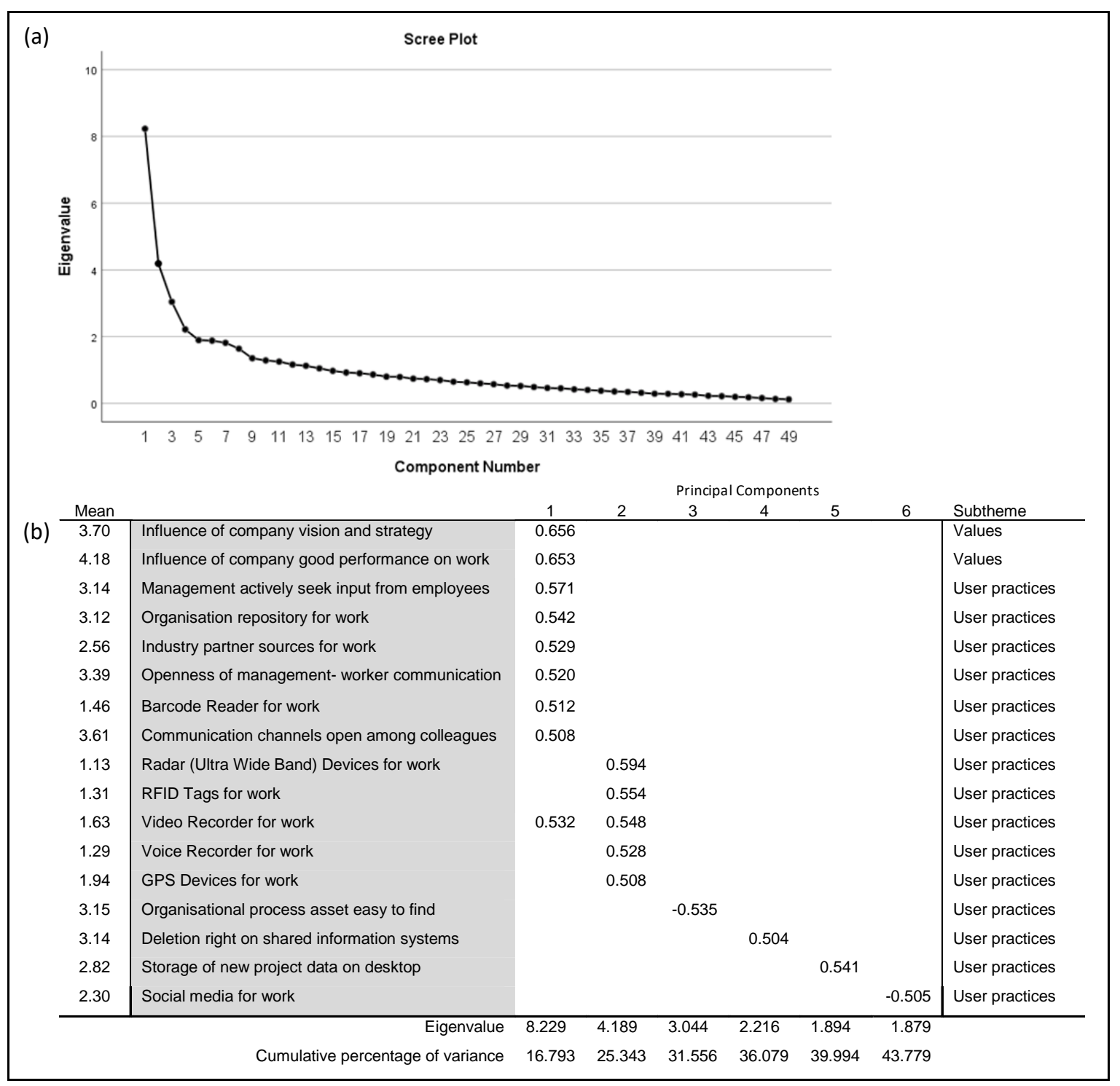

Figure 4: PCA results for user behaviour theme of the information culture survey

To understand the information user behaviour in the studied organisation, the nominated variables in Figure 4(b) are discussed based on the corresponding subthemes in Figure 2. Considering the values of the organisation, the analysed data indicates that the vision, strategy and performance of the organisation have a significant bearing on how its staff use information. Other nominated variables focus on practices within the organisation. They cover data capture, uses of data, data storage and purging of data. Regarding data capture, other than mobile apps and digital cameras, other types of technologies are rarely used. Regarding information use, the organisation adequately shares its performance information. This has a significant influence on its staff doing more good work. There is also indication that information sharing in the organisation works well as survey data shows that organisational process assets are easy to find, and communication channels are open between colleagues.

Other aspects of data use relate to transparency and proactive use of data. Regarding transparency, there is positive indication that management-staff communication works. And with respect to proactive use of data, there is indication that the management of the organisation actively seek input from the employees for decision making. Regarding data storage and purging, an interview with the organisation's IT director revealed that there is a goal to have all project data stored only on the organisation's shared repositories for data protection and recovery reasons. However, the survey data shows that a significant percentage still copy new project data to local computers and removable storage devices. 
Figure 5 shows the PCA results for management style theme of the information culture survey. To check that the data is suitable for factor analysis, Kaiser-Meyer-Olkin and Bartlett's tests were passed. Again, a component loading value of 0.5 is selected as a threshold for including variables. The result shown in Figure 5(a) indicates that there is only one component with eigenvalue greater than 1.0. This component accounts for the majority of variance in the data set with a value of about $62.7 \%$. The mean score of each variable is shown in Figure 5(b).

To understand the management style in the studied organisation, the nominated variables in Figure 5(b) are discussed based on the corresponding subthemes in Figure 2. Considering the data governance environment in the organisation, the analysed data indicates that formal procedures are used for gathering IT related data and sharing IT related knowledge. Regarding technology practices, there is indication that a majority of the people in the organisation are aware of the central IT infrastructure and its uses. This suggests good engagement by the managers of IT resources. However, respondents are split on their take on training provided on IT security which suggests there is still room for improvement.

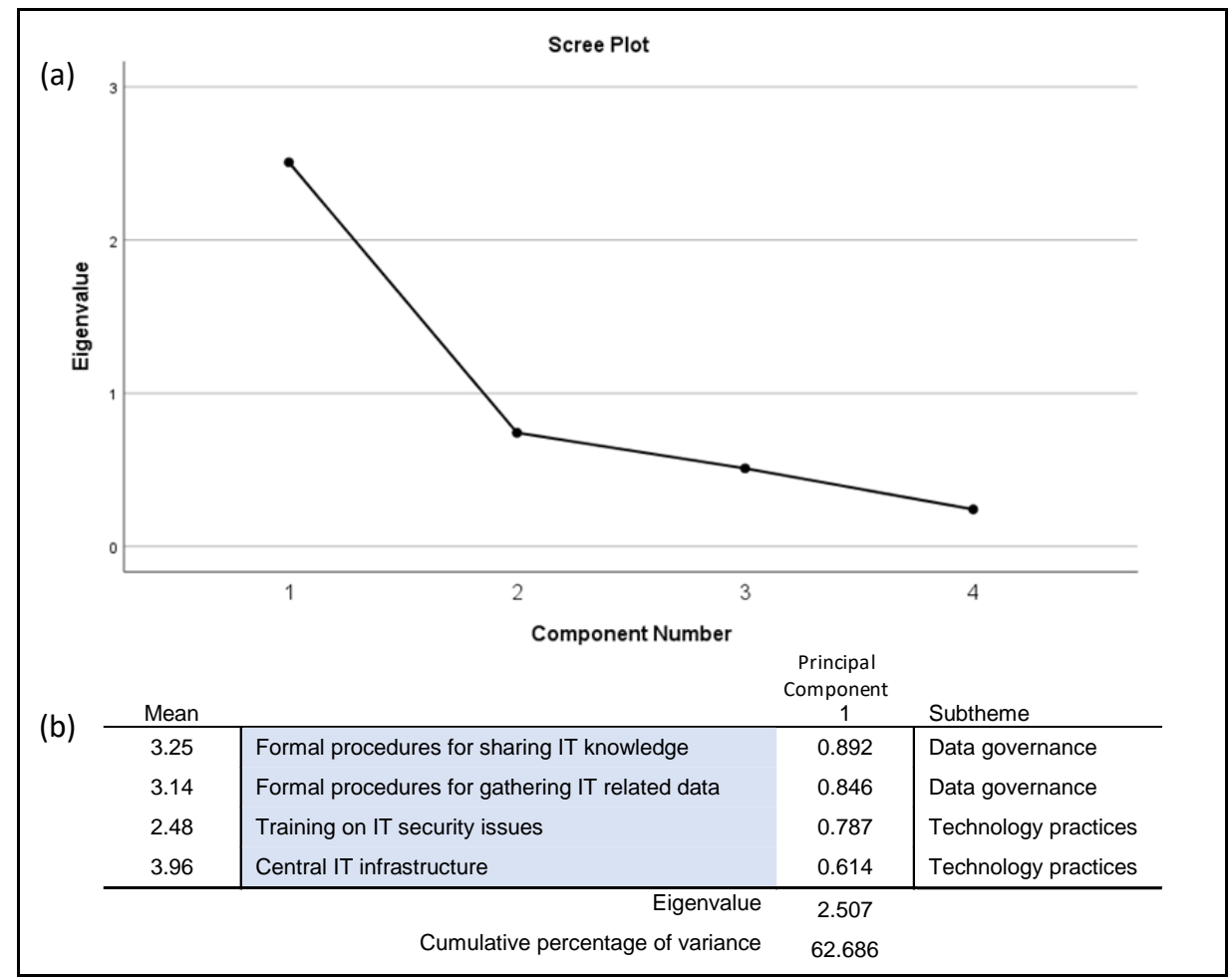

Figure 5: PCA results for management style theme of the information culture survey

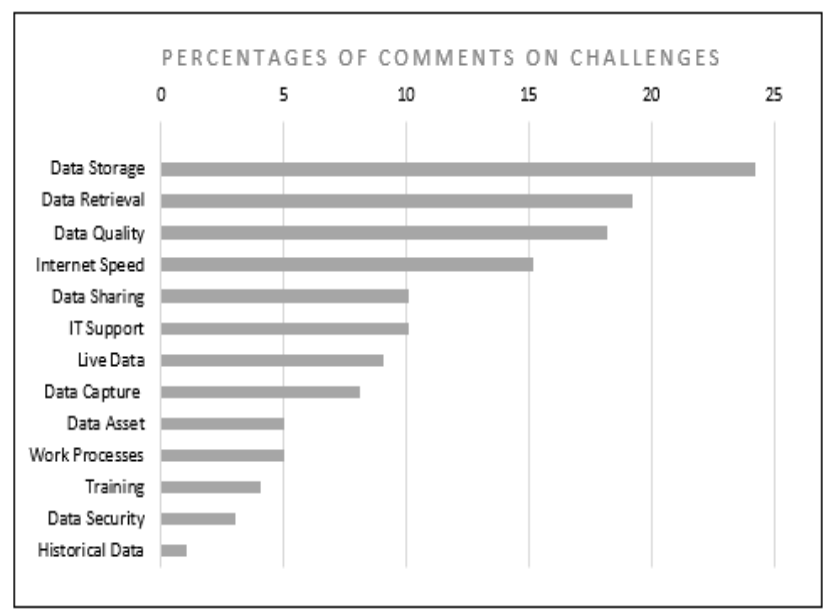

Figure 6: Result of text analysis on information culture survey qualitative data 
Figure 6 shows the result of the analysis on the collected qualitative data. There were 100 comments and the issues of most concern relate to data quality, retrieval, and storage in the organisation. A description of all the issues raised is provided as follows:

- Data storage: there is a general complaint about data storage as a person may need to engage with multiple individuals to retrieve all the data required for a task. The general sense is that available data storage resources are not purposed according to the needs. There are multiple systems used in different parts of the business, resulting in data silo issues. Also, there is a desire to have guidelines to support data storage when working with principal contractors using different data management systems. Because of uncontrolled access to some important repositories within the business, people are worried anyone can move, edit or delete their data. Lastly there is the issue of duplicate folders, resulting in document versioning issues.

- Data retrieval: there are challenges with the retrieval of data because the existing information systems do not adequately support the task. Also, existing processes for storing data are inconsistent, so people store data in different ways, making retrieval difficult.

- Data quality: manual data capture techniques on organisation's construction sites results in data accuracy issues leading to a number of revisions having to be made before reports can be produced. There are also data quality issues due to improper use of information systems, possible as a result of poor training. Another source of the problem relates to data coming from external stakeholders, which the organisation has limited control over. Inadequate quality checks before their application result in data quality issues. Another cause of data quality issues relates to multiple formats. Data available within the organisation sometimes exist in heterogeneous formats and require work for current and future use. Format issues are due in some cases to inconsistent inputting, information handover challenges, duplicity of uploads, edits due to uncontrolled access, and incomplete or incorrect retrieval of data.

- Internet speed: connecting shared repository from construction sites can be very slow because of poor internet service.

- Data sharing: there is a general sense of lack of communication between teams. Data sharing for update and awareness among team members is not sufficient. This particularly affects lessons learned from previous projects. Members of the studied organisation are generally desirous of a centralised repository where they can upload and find updates on specific engineering and operational topics.

- IT support: one out of every ten respondents to the survey raised concerns about the application of multiple information systems, some with overlapping function, with little value. They argue the systems add additional steps to their work and desire a consolidation of the systems. Also, there is a desire to be able to work seamlessly with principal contractor systems while retaining current systems for work. Another desire is an automated system to give notification about the status of a document or data. Lastly, a group within the organisation believes that the capabilities of current systems are nowhere near their full potentials. Consequently, they should be explored further before time, money and effort are expended on new resources.

- Live data: one out of every eleven respondents to the survey argue for the need of real-time data as it will make their work better and help them with time-critical decision making.

- Data capture: in the studied organisation, many data capture exercises are needlessly repeated by multiple persons due to the poor communication between teams. Also, there are several manual data entry tasks that are time consuming. Lastly, due to poor handover between system operators there is inconsistent data input in systems.

- Data asset: lack of organisational process assets because they are not archived. For example, lessons learned are not well captured at the end of projects. Also, data resources applied for successful projects are not converted to process assets.

- Work Processes: the presence of too many procedures and sign offs for access to information resources is inefficient. This leads to unproductive waiting time. For example, a director sign off is required for an engineer to get access to data systems. Another example is the processing of information technology 
requests which requires the downloading and completion of an online request form, signing it, scanning it, and submitting via email.

- Training: one out of every twenty respondents to the survey complained about inadequate training on the use of the information systems provided for work. Others desire the availability of e-learning resources on the use of information systems available for work.

- Data security: at the different operation sites, there is a general sense that low priority is placed on data security, with workers for example complaining about lack of secure data storage.

- Historic data: two individuals underscored the value of historic data to their work and the challenge to get access to such data within the studied organisation.

\subsection{Future state analysis}

The two steps in the proposed framework (Figure 1) for establishing the desired future state of a studied organisation are (i) the clarification of the business' vision and strategy and (ii) the identification of information management best practices. The application of the steps for the studied case are described as follows.

\subsubsection{Company vision and strategy}

Figure 7 summarises the vision and strategy position of the studied organisation's leadership. The goals for the business include growing and improving its capability, winning more work as a result of the competitive advantage achieved through developed capability, and creating an amazing work environment for its employees - a space where there is transparency and collaboration. The organisation's strategy is to attract, develop, and retain the best people. The leadership also plans to acquire assets that will ensure the organisation's financial viability. The vision of the organisation is to become the world's best in its areas of service by maintaining the organisation's value of passionate and ethical work culture.

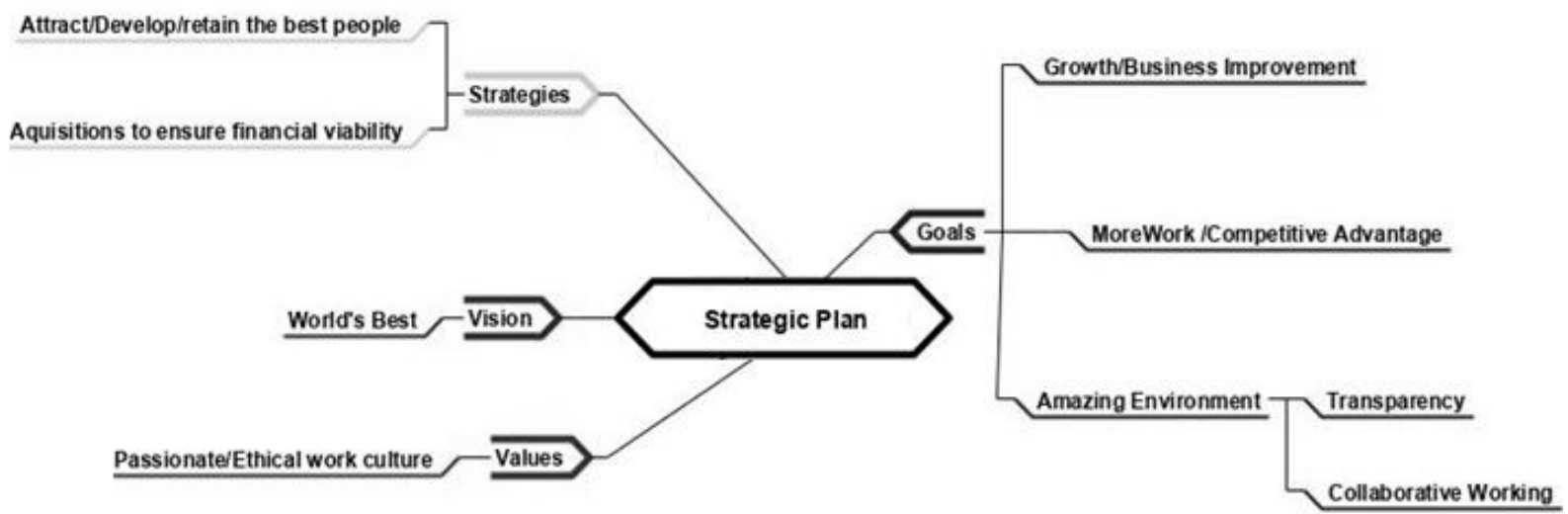

Figure 7: Strategic plan breakdown for studied organisation

\subsubsection{Information Management best practices}

This step was completed using the workshop (Section 4.3) in the proposed strategy development framework. The workshop participants are highly experienced in the best practices for information management. The overarching strategic business plan of the organisation's leadership, as well as clear knowledge of the current state were used as the basis for identifying information management practices appropriate for the organisation's Strategic Information Management (SIM) vision at the tactical and operational levels. The components of the defined vision are depicted in Figure 8 and described as follows:

- Decision support: the studied business has challenges with the availability of accurate, up-to-date data for timely compliance checking and decision making. So, this component is focused on the capability to make mission critical decisions, including predictions through analytics, using data captured within the business processes. This will help to reduce the risk to the business, save on cost, and win more 
work, allowing for the growth of the business. To achieve this, relevant KPIs will be surfaced on dashboards.

- Integrated project control: the studied organisation has departmental processes that are siloed with each department creating procedures and policies that are not properly coordinated with other departments. Consequently, this component is focused on a unified approach to project control for the purpose of achieving smooth business operations. This component is twofold. On one part, it is about linking information systems together e.g., planning and commercial applications for change management. On the other, it is about working to a project governance framework that provides clarity on roles and responsibilities for all stakeholders at each stage of a project's lifecycle. The framework will also integrate work process resources such as clear process maps, procedures, electronic forms, and decision criteria. This component of the SIM vision will promote collaborative working.

- Lean and agile reporting: data capture in studied organisation is inefficient there are challenges with the availability of the most up-to-date, necessary data for work. As a result, this SIM vision component is focused on the provision of access to accurate, up-to-date, project data, in a timely and controlled fashion, to staff who require data for work. It will consider the use of electronic forms on the web, or mobile apps, to capture data; the use of online cloud storage to store collected data; leveraging of live data already on the internet e.g., weather data; and automatic generation of reports by exception. This will eliminate unnecessary paperwork, streamline work processes, and enable timely compliance checking which will ensure transparency within projects.

- Effective data management: this is twofold. On one part, it will focus on the quality of data applied for work. It will deal with issues related to duplication of data, missing data, heterogeneous formats, data accessibility, system upgrades, data storage and eventual purging of data. On the other, it is focused on data security issues including access control and audit trail. This component is core to the SIM vision and holds the other components together.

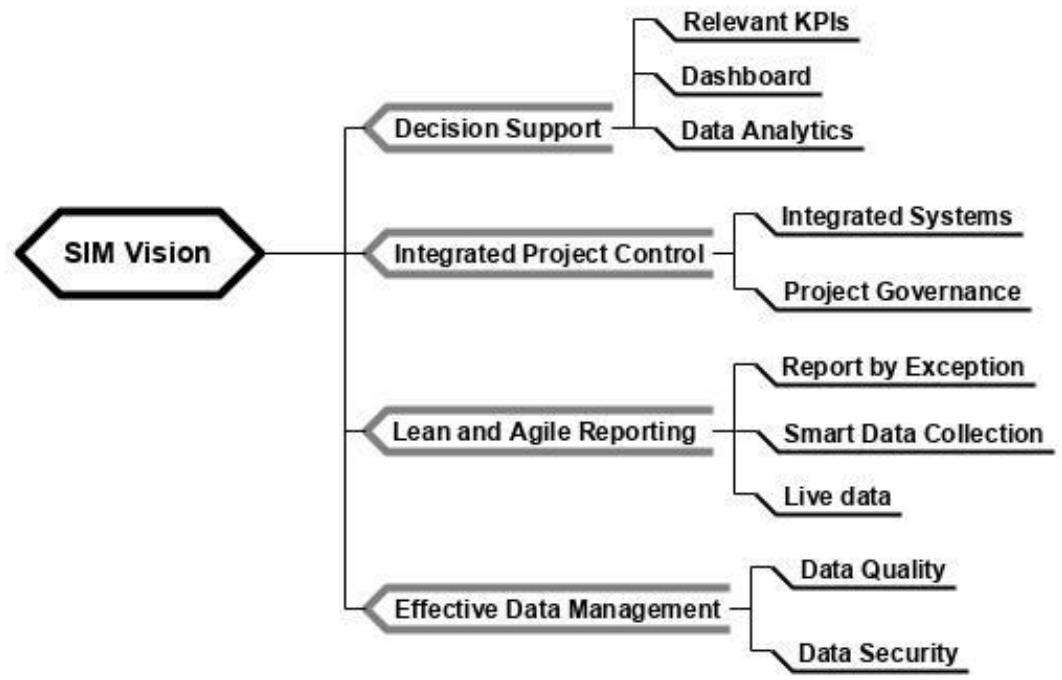

Figure 8: Strategic Information Management (SIM) vision

\subsection{Risk assessment}

Figure 9 shows the SWOT analysis for rationalising a solution for the studied organisation. In terms of strength, the organisation is a leader in its service domain and its leadership is willing to fund innovative ideas with moderate risk profile. The organisation also has experience of collaborating with technology developers. Generally, its staff members have good understanding of the industry in which they operate - including the information management challenges - and are open to new technologies and ways of working. Regarding the organisation's weakness, all the data management issues enumerated in Section 5.1 (Figure 6) are contributing factors. In addition, stakeholders with conflicting interest, and the natural tendency of people to resist change are weakness factors. 
In terms of opportunities, improving on information management in the organisation will lead to increased productivity, improved employee morale, streamlined and integrated work processes, and data driven decision making. These will reinforce the leadership position of the studied organisation. In terms of the threats, cost of some technologies could be prohibitive. Also, maintaining a common information management standard across board when collaborating with other organisations can be challenging. Lastly, regulations in different jurisdiction may mean unique information management requirements per location, leading to additional costs.

In order to achieve the opportunities that match the organisation's strength, staff with knowledge of the current challenges in the work processes can help in identifying the grey areas; and the organisation can leverage existing alliances and past experience with technology developers in streamlining work processes and developing technology tools that can help in improving productivity. Such collaboration can lead to innovation and solidify the organisation's leadership in the construction industry. Such move will be well supported and funded by the company leadership who seem to be open to innovative ideas with moderate risk profile. An opportunity also exists with experienced and curious staff. These individuals can be challenged to think of opportunities to apply data intelligently for decision support and prediction. Engaging them this way will improve their morale as they will feel like they are a part of an important paradigm shift.

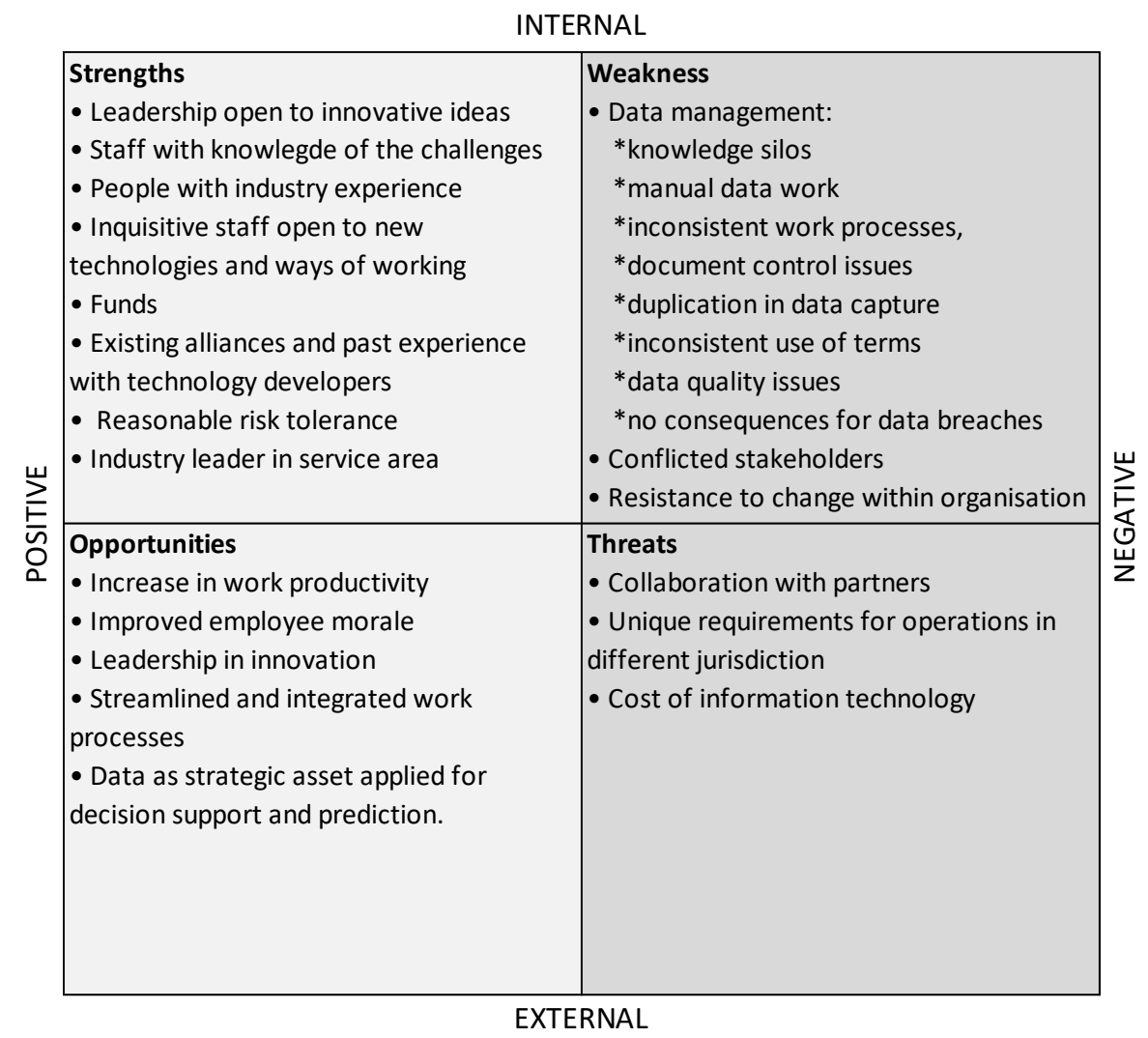

\section{Figure 9: SWOT analysis for SIM vision in studied organisation}

In order to overcome the weaknesses within the organisation and benefit from the opportunities that exist with positive information culture, communication between teams and departments needs to improve. This should be targeted at improving productivity, quality of services, and levels of trust and commitment among co-workers. Such cultural change would allow the sharing of process assets hidden away in the organisation. The resources coming to the fore would reveal the variations in similar processes within the organisation. Attempts by collaborators to benchmark the latter processes would reveal stakeholders with vested interests. Collectively aiming for data as strategic asset in the organisation will help address data issues related to quality, control, capture and semantics.

To address the organisation's vulnerability to outside threats, it needs to pull its weight by applying its strengths. For example, when the construction business partners with organisations with negative corporate or workplace 
culture, this may rub off on the employees of the business. In such a scenario, people with significant industry experience within the studied organisation should be relied on for guidance. The organisation in this case study has over 100 sites across the UK. This means different Information requirements for regulatory compliance in different regions. Again, people with the right experience should be relied on for guidance. Where the cost of information technology is a concern, justification in the form of cost-benefit analysis that is mindful of the direct and indirect benefits of the technology solution should be provided before approval for purchase.

The concluding part of this analysis looks at how the studied organisation can limit its weakness to avoid making the organisation more susceptible to external threats. An important consideration is adequate management of data issues in order to meet regulatory compliance requirements. Also, adequate management of data quality issues by exploiting the capabilities of existing technology resources will prevent unnecessary IT costs. Lastly, where there is resistance to change within the organisation, the company management should: lead change management by sharing a clear vision, invest in resources that can help in educating everyone affected by the change, and engage directly to help address the concerns of those being resistant - particularly the influential stakeholders.

\subsection{Change strategy}

Formulating a change strategy for the described SIM vision requires consideration of the current information culture of the business. In terms of decision support, this study revealed that management of the organisation regularly get input from the employees for decision making. This practice can be used to support data capture for KPIs. Also, the current practice of making decisions based on experience and gut feeling, due to unreliable data, needs to evolve and better lean on the empirical insights that analytics can offer. That will improve risk management in the business. Regarding integrated project control, current practices like good management-staff communication, good information sharing between colleagues, and traceable teamwork effort should be leveraged to achieve integrated project governance. Contrarily, the practice of staff members creating individual document templates for data capture without any coordination must be dealt with by enforcing a common standard.

In achieving lean and agile reporting, the current practice of using mobile apps for work should be extended for data collection to change the current pattern of extensive use of paper-based forms. Also, the importance of sharing the organisation's performance information, a practice employees indicate motivates their work, should be emphasised to gain support for the transition. For effective data management, the occurrence of unauthorised edits needs to be controlled with technology to ensure data integrity. Individuals with conflicted values pushing for specific technology or service provider should be tempered to ensure fit for purpose solutions are adopted. Already, there is report that there is good support from the IT team, and with IT resources. These practices should be continued and extended to include IT sourcing, to ensure reliable internet service is available to support the use of online resources, and staff training on data protection, to curb the practice of copying project data to local computers and removable storage devices.

Based on the information culture survey result, knowledge of the vision, strategy and performance of the organisation has a significant bearing on how its staff use information. So, communicating the SIM vision in a simple way is an important change strategy element. Figure 10 depicts the recurring themes in the change strategy and prioritizes them in three steps. The first step is to address process related issues. This will involve revising process resources, e.g., procedures, document templates and forms, to eliminate redundant steps. Also, this step will help benchmark inconsistent processes within the organisation. The second step is to address all the data issues raised. This will help turn data into an asset that can be applied in prediction and decision support. There is also the need to clearly map the data generation and usage to the processes identified in the first step. The third step is on technology support. This step will involve audit of existing technology resources to identify their limitations and opportunities for further exploitation. The audit exercise will help identify the technology needs in the organisation which will be the basis for technology sourcing or development. Fulfilling the latter step and combining the outcome with live data of excellent quality will help achieve the information management objectives of the organisation and improve its information culture.

Finally, an appointed team is tasked with achieving the future state defined, considering the risk mitigation strategies highlighted in the SWOT analysis and the current information culture of the business. The team will develop a detailed delivery roadmap based on the scope defined for the desired future state. The roadmap will include, at the minimum, estimated timelines, estimate of resources, stakeholder roles and responsibilities, communication plan, deliverables, and the plan for integration and rollouts. 


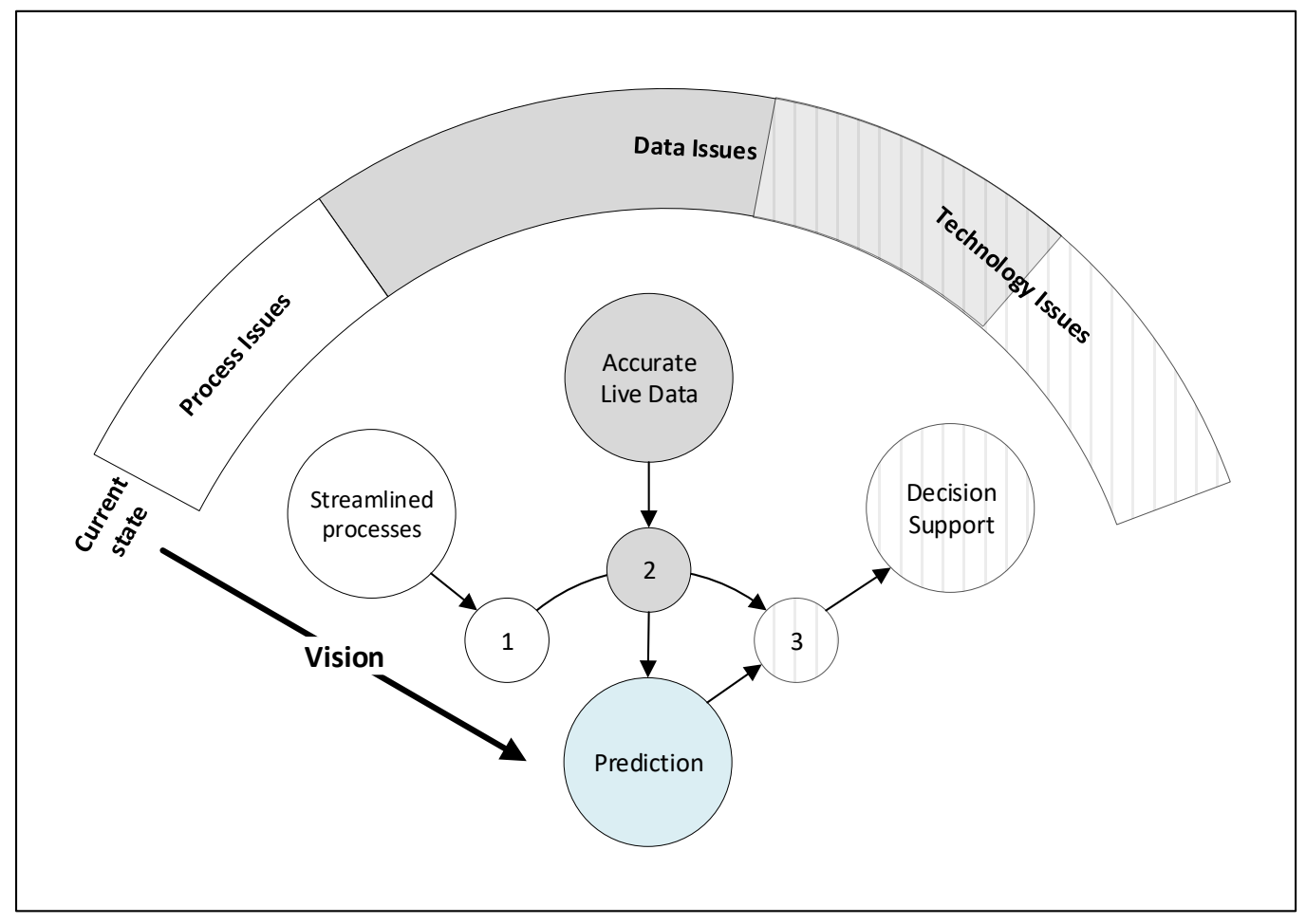

Figure 10: Change strategy map

\section{CONCLUSION}

This study proposes a strategy development framework for information management and demonstrates its application for a construction business. The proposed framework incorporates a cultural analysis framework that combines qualitative and quantitative research techniques in investigating the information culture of an organisation. The results of the culture, process and company vision investigations in the studied organisation were applied in developing a vision for its information management. The culture investigation helped to uncover the user behaviour and management practices, process audit revealed the problems with systems and processes, and vision clarification helped to establish the aspiration of the organisation's leadership. In terms of contribution to the studied organisation, this study helped to outline specific actions for addressing the identified challenges and meeting the information needs for a better information culture - an output valuable to all construction businesses. Given that the combination of circumstances encountered in the studied organisation may be unique, and that businesses regularly revisit their strategies to accommodate pressing enterprise environmental factors, the strategy established in the case study may require reconsideration in new contexts. Notwithstanding, the strategy development framework proposed in this work should be applicable to construction businesses, internationally. For the next step of this research, the implementation of the developed strategy will be examined for its effectiveness and challenges.

\section{ACKNOWLEDGEMENT}

This research was supported by Innovate UK - Partnership number 11228. The opinions, findings and recommendations in this work are those of the authors and do not necessarily reflect the views of the associated organisations. 


\section{REFERENCES}

Adriaanse, A. and Voordijk, H. (2005). 'Interorganizational communication and ICT in construction projects: a review using metatriangulation", Construction Innovation', Construction Innovation, 5(3), pp. 159-177. doi: $10.1108 / 14714170510815230$.

Akinyemi, A.G. (2021). “Information culture survey questionnaire”. Zenodo. doi: 10.5281/zenodo.5599075.

Alvesson, M. (2002). Understanding Organisational Culture. London: Sage publications.

Ankrah, N. A. and Langford, D. A. (2005). 'Architects and contractors: a comparative study of organisational cultures', Construction Management and Economics, 23(6), pp. 595-607.

Anumba, C. E. H. et al. (2006). 'Understanding structural and cultural impediments to ICT system integration: A GIS-based case study', Engineering, Construction and Architectural Management, 13(6), pp. 616-633. doi: 10.1108/09699980610712409.

Austin, S. et al. (2002). 'Modelling and managing project complexity', International Journal of Project Management, 20(3), pp. 191-198. doi: 10.1016/S0263-7863(01)00068-0.

Baiden, B. K., Price, A. D. F. and Dainty, A. R. J. (2006). 'The extent of team integration within construction projects', International Journal of Project Management, 24(1), pp. 13-23.

Bartlett, J. E., Kotrlik, J. W. and Higgins, C. C. (2001). 'Organizational Research : Determining Appropriate Sample Size in Survey Research', Information Technology, Learning, and Performance Journal, 19(1), pp. 43-50.

Brewer, G. and Gajendran, T. (2012). 'Attitudes, behaviours and the transmission of cultural traits: Impacts on ICT/BIM use in a project team', Construction Innovation, 12(2), pp. 198-215. doi: 10.1108/14714171211215949.

Bryman, A. (2012). Social research methods. 4th edn. Oxford: Oxford University Press.

Bryman, A. and Bell, E. (2015). Business Research Methods. 4th edn. New York, NY: Oxford University Press.

Chan, P. W. and Raisanen, C. (2009). 'Editorial: informality and emergence in construction', Construction Management and Economics, 27(10), pp. 907-912.

Choo, C. W. et al. (2006). 'Working with information: Information management and culture in a professional services organization', Journal of Information Science, 32(6), pp. 491-510. doi: $10.1177 / 0165551506068159$.

Dzokoto, F. K. (2015). Information behaviour of construction project actors. Loughborough University. Available at: https://dspace.lboro.ac.uk/dspace-jspui/bitstream/2134/23173/2/Thesis-2016-Dzokoto.pdf.

Gajendran, T. et al. (2012). 'A conceptual approach to studying the organisational culture of construction projects', Australasian Journal of Construction Economics and Building, 12(2), pp. 1-26. Available at: https //dspace.lboro.ac.uk/2134/17893.

Gajendran, T. and Brewer, G. (2007). 'Integration of information and communication technology: Influence of the cultural environment', Engineering, Construction and Architectural Management, 14(6), pp. 523549. doi: 10.1108/09699980710829003.

Gajendran, T. and Brewer, G. (2010). 'Cultural analysis for ICT integration: Case study analysis of a construction project', in Dikbas, A., Ergen, E., and Giritli, H. (eds) Managing IT in contruction/managing construction for tomorrow. CRC Press taylor \& Francis Group, pp. 407-416.

Gajendran, T. and Brewer, G. (2012). 'Cultural consciousness and the effective implementation of information and communication technology', Construction Innovation, 12(2), pp. 179-197. doi: 10.1108/14714171211215930.

Ginman, M. (1993). 'Information culture and business performance', in Information Management: a Scandinavian approach. Scandinavian University Press, pp. 79-94. 
Gürel, E. and Tat, M. (2017). 'SWOT Analysis: A Theorectical Review', The Journal of International Social Research, 10(51), pp. 995-1006. doi: 10.17719/jisr.2017.1832.

Hofstede, G. (2001). Culture's consequences: Comparing values, behaviors, institutions and organizations across nations. Second. Thousand Oaks: Sage publications.

IBM Corporation (2017). 'IBM SPSS Statistics for Windows'. Armonk, New York.

IIBA (2015). A Guide to the Business Analysis Body of Knowledge (BABOK). Toronto: International Institute of Business Analysis.

Issa, R. R. A. and Haddad, J. (2008). 'Perceptions of the impacts of organizational culture and information technology on knowledge sharing in construction', Construction Innovation, 8(3), pp. 182-201. doi: 10.1108/14714170810888958.

Jolliffe, I. (2011). 'Principal Component Analysis', in Lovric, M. (ed.) International Encyclopedia of Statistical Science. Berlin, Heidelberg: Springer.

Van Marrewijk, A. (2007). 'Managing project culture: The case of Environ Megaproject', International Journal of Project Management, 25(3), pp. 290-299. doi: 10.1016/j.ijproman.2006.11.004.

Martin, J. (2002). Organizational Culture: Mapping the Terrain. Sage Publictaions. doi: $10.4135 / 9781483328478$.

Microsoft (2021a). Skype, Available at: https://www.skype.com/en/ (Accessed: April 14).

Microsoft (2021b). Microsoft Teams, Available at: https://www.microsoft.com/en-gb/microsoft-teams/groupchat-software (Accessed: April 14).

Nasrun, M. et al. (2014). 'Impact of Fragmentation Issue in Construction Industry : An Overview 3 Discussions : Fragmentation Issue', in MATEC Web of Conferences :Building Surveying, Facilities Management and Engineering Conference. EDP Sciences, pp. 1-8. doi: 10.1051/matecconf/20141501009.

QSR International Pty Ltd (2017) 'Nvivo 11 for Windows'. Victoria, Australia.

Rousseau, D. M. (1990). 'Assessing Organisational Culture: The Case for Multiple Methods', in Goldstein, I. L. (ed.) Frontiers of Industrial and Organisational Psychology. California: Jossey-Bass Inc.

Saunders, M., Lewis, P. and Thornhill, A. (2009). Research methods for business students. 5th edn. Harlow: Pearson Education Limited.

Schein, E. H. (2004). Organisational culture and leadership. San Francisco: Jossey-Bass.

Smircich, L. (1983). 'Concepts of Cultures and Organisational Analysis', Administrative Science Quarterly, 28(3), pp. 339-358.

Stewart, R. A., Mohamed, S. and Daet, R. (2002). 'Strategic implementation of IT/IS projects in construction: A case study', Automation in Construction, 11(6), pp. 681-694. doi: 10.1016/S0926-5805(02)00009-2.

SurveyMonkey Inc. (2019). SurveyMonkey. Available at: www.surveymonkey.com (Accessed: 22 April 2019).

Svärd, P. (2014). 'The impact of information culture on information/records management: A case study of a municipality in Belgium', Records Management Journal, 24(1), pp. 5-21. doi: 10.1108/RMJ-04-20130007.

Taherdoost, H. (2017). 'Determining Sample Size; How to Calculate Survey Sample Size', International Journal of Economics and Management Systems, 2, pp. 237-239. Available at: https://papers.ssrn.com/sol3/papers.cfm?abstract_id=3224205.

Wilimoft, H. (1997). 'Management and Organization Studies as Science?', Organisation, 4(3), pp. 309-344. doi: $10.1177 / 135050849743002$. 